\title{
Oxidation-Enhanced Evaporation in High-Carbon Ferromanganese
}

\section{Håkon Aleksander Hartvedt Olsen Myklebust ${ }^{1}$ (D) Stefan Andersson $^{2}$. Gabriella Tranell ${ }^{1}$}

Received: 15 September 2020 / Revised: 1 February 2021 / Accepted: 9 February 2021 /

Published online: 20 March 2021

(c) The Author(s) 2021

\begin{abstract}
Thermal fume formation is a problem in manganese ferroalloy production and the metal production industry at large. A better understanding of the mechanisms of fume formation and the operational parameters affecting the fume formation rate may help in reducing and managing fuming. This paper aims to investigate the effects of oxygen content and gas flow rate on the fuming rate and fume particulate properties for liquid high-carbon ferromanganese. The fuming rates were attained experimentally by measuring the fume flux with respect to oxygen content and gas velocity above the metal melt. The generated fumes were also characterized in terms of particle size and element distribution between fume and melt. The fuming rates were found to steadily increase with increasing oxygen content and flow rate of the gas up to a point where the curve flattens, following theoretical predictions. However, the highest flux values measured were above the theoretical limitations of the evaporation flux in vacuo given the alloy bulk composition. It is hypothesized that the high rate of fuming is caused by an increased manganese activity at the alloy surface due to local decarburization of the alloy in contact with the oxidizing gas.
\end{abstract}

Håkon Aleksander Hartvedt Olsen Myklebust

hakon.a.h.olsen@ntnu.no

Stefan Andersson

stefan.andersson@sintef.no

Gabriella Tranell

gabriella.tranell@ntnu.no

1 Norwegian Institute of Science and Technology, Alfred Getz Vei 2, 7034 Trondheim, Norway

2 Sintef Energy, Alfred Getz Vei 2, 7034 Trondheim, Norway 


\section{Graphical Abstract}
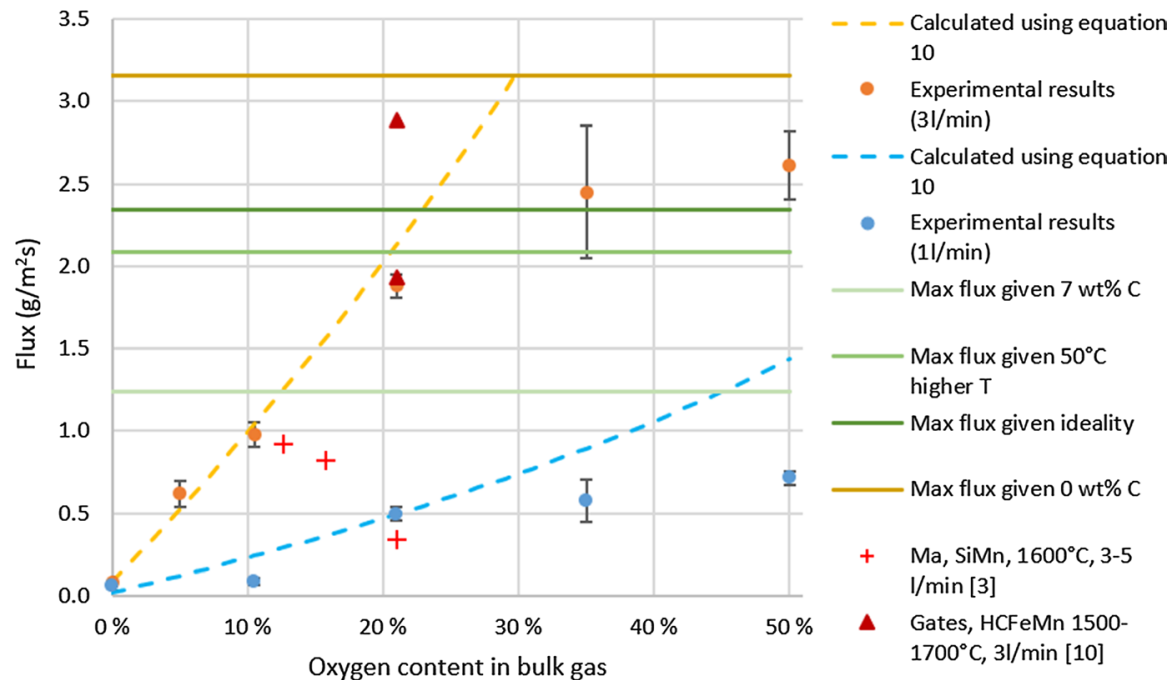

Keywords Modelling $\cdot$ Fume formation · Oxidation $\cdot$ Ferromanganese

\section{Introduction}

Manganese is extensively used as an alloying element for the iron- and steelmaking industry in the form of ferromanganese and silicomanganese [1]. The production of ferromanganese commonly takes place in an electric submerged arc furnace through carbothermic reduction of manganese ores. Ferromanganese alloys can be classified into high-carbon ([C]-7.0wt\%), medium-carbon ([C]<2.5wt\%), and low-carbon $([\mathrm{C}]<0.5 \mathrm{wt} \%)$ grades [2]. The liquid ferromanganese metal is cast at temperatures above $1500{ }^{\circ} \mathrm{C}$ in air, where the vapor pressure of manganese is high, typically $>0.01 \mathrm{~atm}$.

Reactions between the Mn vapor and oxygen in the atmosphere leads to the formation of oxide fumes, and these fumes contribute not only to product losses, but are also detrimental to the working environment [3]. Early studies focusing on modelling of the generic metal-oxidizer system by Wagner [4], Turkdogan et al. [5] and Rosner [6] have laid the theoretical foundation for modelling evaporation and oxidation rates. However, development and validation of kinetic models for more specific applications such as high-carbon ferromanganese (HCFeMn) have not yet been performed.

The main goal of the current study is to experimentally investigate the effects of increased oxygen content and gas flow rate over liquid high-carbon ferromanganese (HCFeMn) on the fuming/oxidation rate, and to evaluate these results using the methodology for oxidation-enhanced evaporation developed by Rosner 
[6] and Turkdogan et al. [5]. Furthermore, an additional goal is to increase our knowledge of fume-oxide particle growth and clustering in ferromanganese fumes under these conditions, as well as studying minor element distribution between liquid metal and condensed fumes as a function of gas flow rate and composition.

\section{Theory and Literature}

Turkdogan et al. [5] established the theory of direct metal oxidation based on metal evaporation, where the formation of oxide mists enhances the fume flux. Theory states that the metal evaporation rate is rate-limiting at ambient oxygen levels above a certain "critical" value, and that below this value, for a given gas flow-rate and temperature, the flux is directly proportional to the ambient oxygen partial pressure following Eq. 1.

$$
J_{i}=\frac{\alpha h}{R T} p_{\mathrm{O}_{2}}
$$

where $\mathrm{J}_{i}$ is the fume flux in $\mathrm{g} / \mathrm{m}^{2} \mathrm{~s}, R$ is the ideal gas constant, $T$ is the temperature in Kelvin, $\mathrm{p}_{\mathrm{O}_{2}}$ is the ambient partial pressure of oxygen in pascal, $\mathrm{h}$ is the average film mass-transfer coefficient for the transport of oxygen through the aerodynamic diffusion boundary layer which is calculable for known flow conditions, and $\alpha$ is the

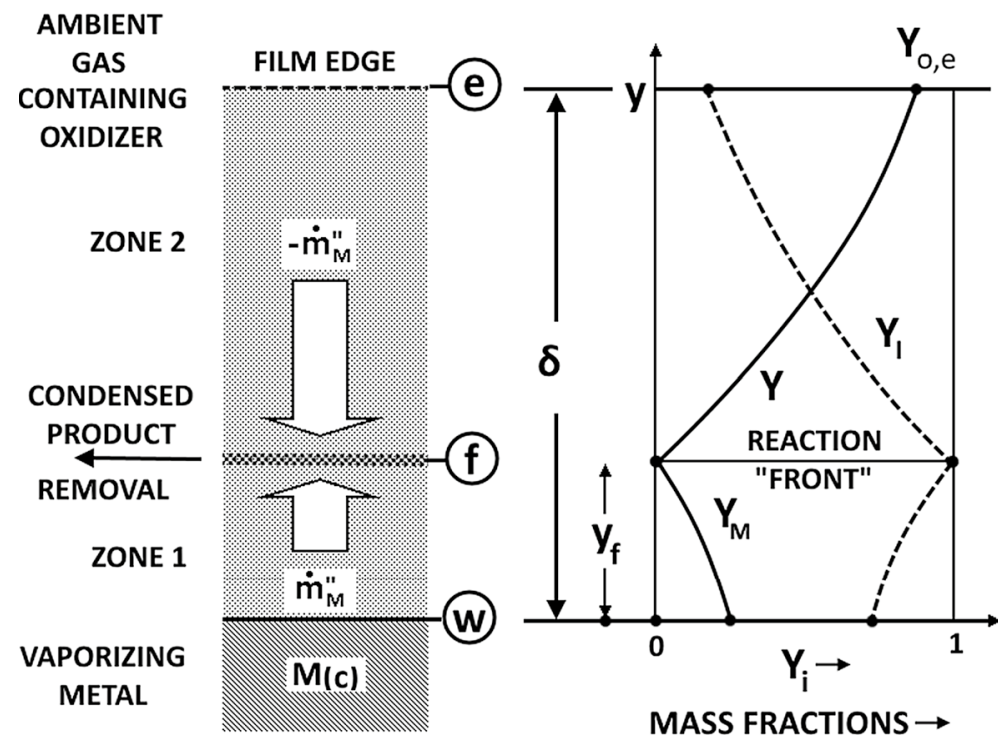

Fig. 1 Reaction and condensation-enhanced metal vaporization; two-film model and notation. Redrawn from Rosner [6]. Here, e denotes the film edge, $f$ the reaction front, w the liquid surface, $\dot{m}_{\mathrm{M}}^{\prime \prime}$ the metal flux, $\mathrm{Y}$ the mass fraction, I the inert gas, $\mathrm{M}$ the metal, and $\mathrm{O}$ oxygen. $\mathrm{y}$ is the distance from the surface and $\delta$ the film thickness, often referred to as the diffusion layer thickness 
number of moles of metal vapor required to combine with one mole of oxygen, and is valid for any metal.

Ma et al. used Factsage to generate a stability diagram for manganese and its oxides for different oxygen partial pressures and temperatures, where it can be seen that at $1500{ }^{\circ} \mathrm{C}$, oxygen pressures above $10^{-15}$ atm will lead to the formation of manganese monoxide (solid), and as the temperature decreases, higher oxides become stable. The oxide formation happens through several reactions which includes a number of phases: $\mathrm{Mn}(\mathrm{g}), \mathrm{MnO}(\mathrm{s}), \mathrm{Mn}_{3} \mathrm{O}_{4}\left(\mathrm{~s}_{1}\right), \mathrm{Mn}_{2} \mathrm{O}_{3}\left(\mathrm{~s}_{2}\right)$, and $\mathrm{MnO}_{2}(\mathrm{~s})$ where $\mathrm{Mn}_{3} \mathrm{O}_{4}\left(\mathrm{~s}_{1}\right)$ and $\mathrm{Mn}_{2} \mathrm{O}_{3}\left(\mathrm{~s}_{2}\right)$ represent tetragonal (low-temperature) $\mathrm{Mn}_{3} \mathrm{O}_{4}$ and cubic (high-temperature) $\mathrm{Mn}_{2} \mathrm{O}_{3}$, respectively [7, 8]. At the surface temperature used in this work $\left(1550{ }^{\circ} \mathrm{C}\right)$, the relevant phases for the diffusion layer are $\mathrm{Mn}(\mathrm{g})$ and $\mathrm{MnO}(\mathrm{s})$ which further oxidizes and agglomerates in the bulk gas.

Rosner's work on this "oxidation-enhanced" evaporation [6] confirmed the results of Turkdogan et al. in highly dilute isothermal systems, and also found additional effects based on the condensation process as a limit for fuming in oxidizer-rich ambient gasses. He described the system graphically as shown in Fig. 1, and while both Rosner and Turkdogan's work was generic, their calculations are applicable for the $\mathrm{Fe}-\mathrm{Mn}$-system and both $\mathrm{Fe}$ and $\mathrm{Mn}$ are mentioned alongside $\mathrm{Ni}, \mathrm{Co}$ and $\mathrm{Cu}$ in their work, and as such the metal " $\mathrm{M}$ " in the following equations relates to $\mathrm{Mn}$ in the system studied in this work. The figure describes how the concentration of metal and oxygen goes down toward the reaction "front" inside the diffusion layer where the concentration of both is 0 as the oxidation reaction is very fast and the condensed product no longer affects the diffusion and reaction. The higher concentration of oxygen, the steeper the concentration curve in zone 2 will be, and the closer to the surface the reaction "front" will be. Similarly a higher fraction of metal vapor at the surface increases the diffusion rate in zone 1 which pushes the reaction "front" away from the surface until it again is in equilibrium with the diffusion rate of oxygen. Both cases would increase the flux of metal from the surface, and as such would increase the fuming rate.

Rosner's model is explained in further under the modelling section, and is an integral part of this work.

You et al. [2] studied evaporation of manganese during the oxygen refining process experimentally, and confirmed that due to the high vapor pressure of manganese in ferromanganese melts there is a significant loss due to evaporation. An empirical equation for the evaporation loss was derived based on a sampling system, and is shown in Eq. 2:

$$
\frac{\left(W_{\mathrm{Mn}}\right)_{\mathrm{evap}}}{W_{\text {metal }}}=\beta \cdot \sum_{i=1}^{n}\left(\frac{\left(P_{\mathrm{Mn}}\right)_{i}}{\sqrt{T_{i}}} \cdot\left(t_{i+1}-t_{i}\right)\right)
$$

where $\left(W_{\mathrm{Mn}}\right)_{\text {evap }}$ is the evaporation loss of manganese in kilograms, $W_{\text {metal }}$ is the amount of hot metal charged(iron), " $i$ " is the order of sampling, and $\left(\mathrm{t}_{i+1}-\mathrm{t}_{i}\right)$ is the time interval between sampling in minutes. The apparent vaporization coefficient, $\beta$, was found to be significantly affected by the fraction of top blown oxygen, which concurs with the previously discussed theories. 
Lee and Kolbeinsen [9] studied the kinetics of the oxygen refining process for high-carbon ferromanganese, where they found that when the vapor pressure of manganese vapor becomes high, the rate of manganese loss is controlled by the mass transfer of manganese vapor through the diffusion boundary layer adjacent to the interface of melt and gas, and that the formation of $\mathrm{MnO}$ mist increases the melt temperature. As the temperature is an important factor in the evaporation rate of manganese, this can potentially have an impact on the fuming rates.

Gates et al. $[10,11]$ also studied fuming rates in ferromanganese, with a focus on the effect of water vapor in the bulk gas. The rate of fuming was found to decrease with increased water content in the atmosphere and that fume particles were found in larger clusters rather than fine dust with moist atmospheres. While this effect was not fully explained, a decrease in temperature with the addition of water to the atmosphere may partly explain the results. They also found notable amounts of $\mathrm{ZnO}$ in the dust from their experiments with higher water vapor content.

\section{Experimental Procedures}

The experimental setup is shown in Fig. 2, and has been used in previous studies by Kero et al. [12], Næss et al. [13], Gates et al. [10], and Ma et al. [7]. A standard grade HCFeMn was used with a composition as shown in Table 1. The gas flow rate was controlled with a mass flow controller in each gas tube allowing for controlled mixing of oxygen and nitrogen, with the total flow varying from 1 to $5 \mathrm{l} / \mathrm{min}$, which

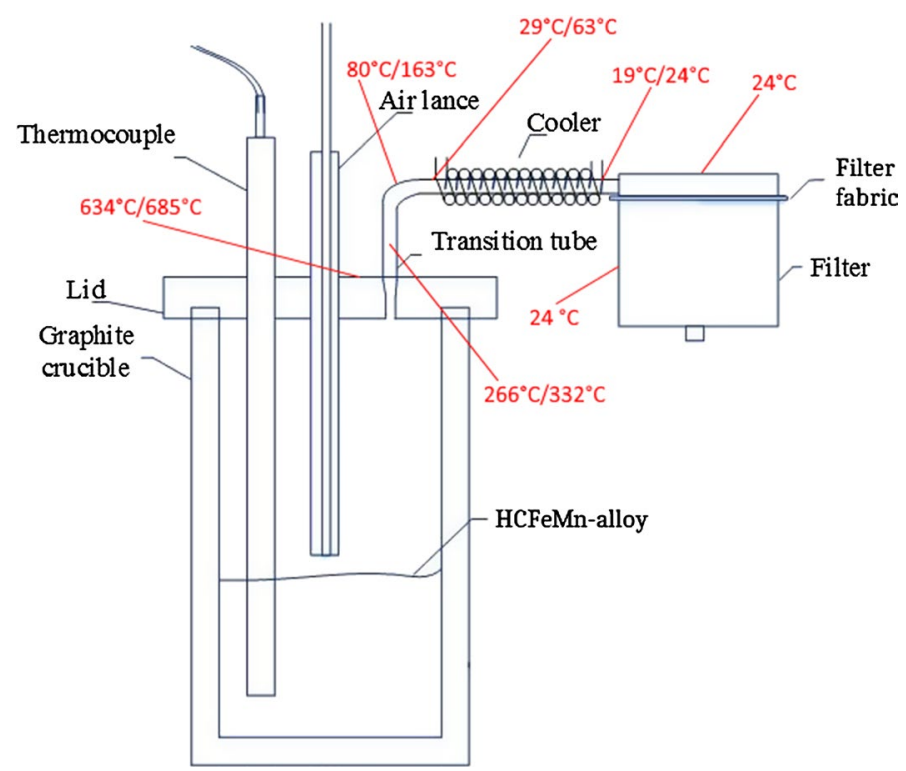

Fig. 2 The experimental setup with average temperatures (with/without gas flow) as measured during the 16 first experiments. The experiments were carried out with a temperature of $1550{ }^{\circ} \mathrm{C}$ in the alloy 
Table 1 Chemical composition of the HCFeMn used in the experiments as measured by ICP and given in $\mathrm{WT} \%$

\begin{tabular}{llllll}
\hline $\mathrm{Mn}$ & $\mathrm{Fe}$ & $\mathrm{C}$ & $\mathrm{P}$ & $\mathrm{Na}$ & $\mathrm{Si}$ \\
\hline $72.1 \%$ & $12.3 \%$ & $6.5-7.5 \%$ & $0.137 \%$ & $0.06 \%$ & $0.02 \%$ \\
$\mathrm{~S}$ & $\mathrm{Mg}$ & $\mathrm{K}$ & $\mathrm{Pb}$ & $\mathrm{Al}$ & $\mathrm{Zn}$ \\
$0.009 \%$ & $0.004 \%$ & $0.003 \%$ & $0.003 \%$ & $0.001 \%$ & $0.001 \%$ \\
\hline
\end{tabular}

The range in the carbon content is specified by the supplier

corresponds to a gas velocity of approximately 5.28 to $26.39 \mathrm{~m} / \mathrm{s}$ at the lance tip. Each experiment was subjected to a gas flow for at most 20 minutes at $1550{ }^{\circ} \mathrm{C}$, and temperature measurements were conducted at several points between the crucible and filter before and after the gas flow was initiated. Experiments exhibiting a high fume formation had their gas flow duration cut short to avoid clogging of the gas outlet system, and in the experiments with the highest flow rate the fume formation was too high for the system to handle leading to constant fume leakage through the safety valve. The latter lead to the flux data from experiments with $51 / \mathrm{min}$ flow rate being removed from the flux data pool as the fluxes measured were very inaccurate.

After each experiment, the dust from the fume was collected at three sites: the tube connecting the cooler to the lid, named the "transition tube", the cooler, and the filter. An average of more than $70 \%$ of the dust was collected in the filter, $10 \%$ in the cooler and the rest in the transition tube. Figure 2 shows the average deposition temperatures, with the first number showing the temperature just before the gas flow was turned on, and the second showing the temperature in the middle of the experiment. The deposition temperatures measured was considered sufficiently established after measuring across 16 experiments, and further measurements were not deemed necessary for the remainder of the experiments.

Table 1 shows the chemical composition of the metal used in the experiments as measured by inductively coupled plasma-mass spectroscopy (ICP-MS). The range in the carbon content is specified by the supplier, but since the experiment occurs in a graphite crucible, the bulk carbon concentration is expected to approach saturation during the experiment.

After each experiment, the amount of dust in each part of the outflow system was measured by comparing the weight of each individual component before and after the experiment. The components were thoroughly cleaned and dried in between each experiment. As soon as the measurements were completed, the dust from each site was gathered for further studies. The resulting mass flux $\left(\mathrm{J}_{\mathrm{m}}\right)$ from each experiment was calculated from the total mass increase in the filter system, following Eq. 3:

$$
J_{\mathrm{m}}=\mathrm{m} / \mathrm{A} t
$$

where $\mathrm{m}$ is the measured dust mass, $\mathrm{A}$ is the alloy-to-air surface area as measured by the crucible cross-section, and $t$ is the holding time. There was no observable slag formation during the experiments.

To investigate the importance of oxygen access to the reactions, experiments were conducted with different gas mixtures between oxygen and air. Table 2 shows the list of all experiments performed for this study. Synthetic air, with a composition 
of $21 \% \mathrm{O}_{2}$ and $79 \% \mathrm{~N}_{2}$, was used together with pure $\mathrm{N}_{2}$ and $\mathrm{O}_{2}$ to reach the required concentrations. All gasses were at 5.0 quality, with maximum amount of $\mathrm{H}_{2} \mathrm{O}$ equal to $5 \mathrm{ppmX}$.

Dust generated during fuming was analyzed using ICP-MS, laser diffraction (LD), and imaged by scanning electron microscopy (SEM), to see how both elemental and size distributions are affected by the varying flow rates and oxygen concentrations. LD is a method of measuring the particle size distribution by measuring the angular variation in intensity of light scattered as a laser beam passes through a dispersed particulate sample [14], and in this work the equipment used for LD was a Coulter LS230 [15].

\section{Modelling}

Rosner derived a formula for the critical transition pressure of oxidizing agents valid even when approaching pure gaseous oxidizers, shown in Eq. 4. Assuming oxygen contents below this value, he introduced the formula shown in Eq. 6, which defines the flux ratio between a system with no oxygen in the ambient gas and one with a given oxygen partial pressure;

$$
Y_{\mathrm{O}, e}^{*}=1-\left(\frac{1}{1-Y_{\mathrm{M}, w}}\right)^{-(r / D)\left(F_{R X N}^{*}-1\right)}
$$

where $\mathrm{Y}_{\mathrm{O}, e}^{*}$ is the critical mass fraction of oxygen in the ambient gas, $\mathrm{Y}_{\mathrm{M}, w}$ is the mass fraction of metal vapor at the gas-metal interface, $r$ is the mass of oxidizer that

Table 2 Experimental matrix, all experiments performed at $1550{ }^{\circ} \mathrm{C}$, with a holding time of 20minutes

\begin{tabular}{lll}
\hline $\mathrm{O}_{2}$-content $(\%)$ & Gas flow rate $(1 / \mathrm{min})$ & No of parallels \\
\hline 0 & 1 & 3 \\
10.5 & 1 & 4 \\
21 & 1 & 3 \\
35 & 1 & 2 \\
50 & 1 & 2 \\
0 & 3 & 3 \\
5 & 3 & 5 \\
10.5 & 3 & 3 \\
21 & 3 & 3 \\
35 & 3 & 6 \\
50 & 3 & 3 \\
10.5 & 5 & $2^{*}$ \\
21 & 5 & $3^{*}$ \\
35 & 5 & $4^{*}$
\end{tabular}

*5 $1 /$ min flow rate experiments were not viable for flux analysis as the high flow lead to substantial fume leakage, but dust was still analyzed. Between 2 and 6 experiments were successfully performed with each set of parameters 
reacts with a unit mass of metal vapor, $\mathrm{F}_{R X N}^{*}$ is the critical reaction factor defined in Eq. 5, and D is an oxidizer-to-metal diffusion density ratio defined by Eq. 8 .

$$
\begin{gathered}
F_{R X N}^{*}=\dot{m}_{\mathrm{vac}}^{\prime \prime} / \dot{m}^{\prime \prime} 0 \\
F_{R X N}=1+\frac{\left(\overline{D_{O-I} \rho}\right)_{2}}{\left(\overline{D_{M-I}}\right)_{1}} \cdot \frac{1}{r} \cdot \frac{\ln \left[1 /\left(1-Y_{O, e}\right)\right]}{\ln \left[1 /\left(1-Y_{M, w}\right)\right]}
\end{gathered}
$$

$\dot{m}^{\prime \prime}$ is here the flux given no homogeneous chemical reaction, which in our case relates to an ambient oxygen partial pressure at effectively zero, and $\dot{m}_{\text {vac }}^{\prime \prime}$ is the maximum evaporation flux which can be given by the Hertz-Langmuir expression shown in Eq. 7 according to kinetic theory:

$$
\dot{m}_{\mathrm{vac}}^{\prime \prime}=\frac{\alpha_{s}}{4} \cdot \frac{p_{\mathrm{Mn}, \mathrm{eq}}}{k T_{w}} \cdot\left(\frac{8 k T_{w}}{\pi m_{\mathrm{Mn}}}\right)^{1 / 2} \cdot \mathrm{Mn}
$$

where $\alpha_{s}$ is the sticking factor, which describes the ratio between the number of molecules that desorb and adsorb from the same surface during a time interval, and is considered to be 1 in the case of a liquid metal. $\mathrm{p}_{\mathrm{Mn}, \mathrm{eq}}$ is the equilibrium partial pressure of manganese vapor at the metal surface, $\mathrm{k}$ is Boltzmann's constant, $\mathrm{T}_{w}$ is the temperature at the metal surface, and $\mathrm{M}_{\mathrm{Mn}}$ is the molecular mass of manganese.

$$
D=\left(\overline{D_{\mathrm{O}-\mathrm{I}} \rho}\right)_{2} /\left(\overline{D_{\mathrm{M}-\mathrm{I}}}\right)_{1}
$$

Here $\left(\overline{D_{i-j} \rho}\right) x$ is the mean Fickian binary diffusion coefficient for species $\mathrm{i}$ and $\mathrm{j}$ multiplied by the total mass density of the gas mixture in zone $\mathrm{x}$ relating to the zones in Fig. 1. O relates to the oxidizer, I the inert gas, and $\mathrm{M}$ the metal vapor. $\mathrm{Y}_{i, j}$ is the mass fraction of species $i$ at surface $\mathrm{j}$ relating to Fig. 1.

With this, the critical oxygen fraction where evaporation becomes the rate limiting factor can be calculated if the flux with no oxidizer present can be calculated or found through experiments. The theoretical fluxes given an ambient oxygen partial pressure below this critical fraction can also be calculated.

This model based on Rosner's reaction factor $\mathrm{F}_{R X N}$ [6] was used alongside the experimental data to predict the experimental yield. The model was based on Eq. 6, where the experimental value for $0 \% \mathrm{O}_{2}$ is multiplied with the calculated reaction factor $\mathrm{F}_{R X N}$ at each point. The values for diffusion coefficients and mass fractions at the different boundaries were calculated for each $1 \% \mathrm{O}_{2}$ starting at $0 \%$, and used to generate the $\mathrm{F}_{R X N}$ for each point using Eq. 6. The flux was then estimated at each point according to Eq. 9.

$$
J_{i}=J_{0 \%} \cdot F_{R X N, i}
$$

where $\mathrm{i}$ denotes the $\mathrm{O}_{2}$ percentage for each individual flux value and reaction factor. When utilizing this model it is important to note that if any assumptions concerning either the diffusion density ratio, mass fraction of the metal in the vapor, or oxygen in the bulk gas are compromised, then the model values from Eq. 6 must be 
recalculated. This is due to the flux calculation being very sensitive with respect to these parameters.

The theoretical value for the manganese evaporation flux in vacuo was also calculated using the Hertz-Langmuir expression as shown in Eq. 7. In theory this value should constitute an "upper bound" which the flux values would converge toward as the oxygen content is increased [6]. The partial pressure of manganese can be calculated from the formula for Gibbs free energy, which rearranged for partial pressure is shown in Eq. 10 [16]:

$$
p_{\mathrm{Mn}, \mathrm{eq}}=101325 \cdot a_{\mathrm{Mn}} \cdot \exp \left(\frac{241780-104.46 \cdot T}{-8.314 \cdot T}\right)(P a)
$$

where $\mathrm{a}_{\mathrm{Mn}}$ is the activity of manganese in the melt and $\mathrm{T}$ is the temperature in Kelvin. The activity of manganese was calculated using Factsage 7.3 [8] with chemical compositions given in Table 1 , and an initial carbon content of $7 \mathrm{wt} \%$, which represents the system's carbon saturation. The software performs Gibbs energy minimization to calculate the distribution of elements in the different phases, using among others the Gibbs-Duhem equation. This equation does not take surface effects into consideration.

Diffusion coefficients of $\mathrm{Mn}-\mathrm{N}_{2}$ were calculated using Chapman-Enskog kinetic theory $[17,18]$ for an intermolecular interaction potential in the form of a Morse potential in a similar manner as performed previously for the $\mathrm{Mn}-\mathrm{Ar}$ system [19]. The interaction potential was calculated using quantum chemistry. More specifically, the CCSD(T) (coupled cluster with single and double excitations and a perturbative treatment of triple excitations) method was used with the aug-cc-pVQZ basis set [20, 21]. The CFOUR code [22, 23] was used for all CCSD $(T)$ calculations.

Diffusion coefficients of a gas mixture of A and B were calculated by [18]

$$
D_{\mathrm{AB}}=\frac{3}{16} \sqrt{\frac{2(R T)^{3}}{\pi}\left(\frac{1}{M_{\mathrm{A}}}+\frac{1}{M_{\mathrm{B}}}\right)} \frac{1}{N_{A} p \sigma_{\mathrm{AB}}^{2} \Omega_{D, \mathrm{AB}}}
$$

where $\sigma_{\mathrm{AB}}$ is the average of the individual hard-sphere radii

$$
\sigma_{\mathrm{AB}}=\frac{1}{2}\left(\sigma_{\mathrm{A}}+\sigma_{\mathrm{B}}\right)
$$

and $\Omega_{D, \mathrm{AB}}$ is the temperature-dependent collision integral, which describes the deviation of a real gas from the ideal hard-sphere gas behavior. In the case of $\mathrm{Mn}$ and $\mathrm{N}_{2}$ the interaction potential has been fitted to a Morse potential expression, for several angles of approach, $\theta$, of the $\mathrm{Mn}$ atom toward the $\mathrm{N}_{2}$ molecule:

$$
V(R, \theta)=D_{e, \theta}\left(e^{-2 a\left(R-R_{e, \theta}\right)}-2 e^{-a\left(R-R_{e, \theta}\right)}\right)
$$

where $R$ is the center-of-mass distance between $\mathrm{Mn}$ and $\mathrm{N}_{2}$. By placing the $\mathrm{N}_{2}$ bond vector along the $z$-axis and the $\mathrm{N}_{2}$ center of mass at the origin, one can express the system in spherical coordinates $R, \theta, \phi . R$ then lies along the vector between the Mn atom and the $\mathrm{N}_{2}$ center of mass and the $\theta$ angle is the angle between this vector and 
the $\mathrm{N}_{2}$ bond vector. The $\phi$ angle describes rotation of $\mathrm{Mn}$ around the $\mathrm{N}_{2}$ bond. Subsequently, the effective interaction potential was calculated by averaging the angledependent potential over all $\mathrm{Mn}-\mathrm{N}_{2}$ angles:

$$
V_{\text {eff }}(R)=\frac{\int_{0}^{\pi} \int_{0}^{2 \pi} V(R, \theta) \sin \theta \mathrm{d} \theta \mathrm{d} \phi}{\int_{0}^{\pi} \int_{0}^{2 \pi} \sin \theta \mathrm{d} \theta d \phi}=\int_{0}^{\frac{\pi}{2}} V(R, \theta) \sin \theta \mathrm{d} \theta
$$

with the second equality being due to the potential being cylindrically symmetric around the $\mathrm{N}_{2}$ bond and also symmetric with respect to approach of Mn toward either end of $\mathrm{N}_{2} . V_{\text {eff }}(R)$ was thereafter fitted to a new set of Morse parameters:

$$
V_{\mathrm{eff}, \mathrm{fit}}(R)=D_{\mathrm{e}, \mathrm{eff}}\left(e^{-2 a_{\mathrm{eff}}\left(R-R_{\mathrm{e}, \mathrm{eff}}\right)}-2 e^{-a_{\mathrm{eff}}\left(R-R_{\mathrm{e}, \mathrm{eff}}\right)}\right)
$$

with $D_{\text {e,eff }}=88.2 \mathrm{~K}, R_{\mathrm{e}, \mathrm{eff}}=4.93 \AA$ and $a_{\mathrm{eff}}=1.04 \AA^{-1}$. Using these parameters, values of $\Omega_{D, \mathrm{AB}}$ were interpolated from tabulated values for Morse potentials for relevant temperatures [24].

Diffusion coefficients of the $\mathrm{N}_{2}-\mathrm{O}_{2}$ gas mixture were also calculated using Eq. (11) but with literature Lennard-Jones parameters [18] and the corresponding expressions for the collision integral. This resulted in diffusion coefficients of $3.66 \mathrm{~cm}^{2} / \mathrm{s}$ for $\mathrm{Mn}-\mathrm{N}_{2}$ and $4.37 \mathrm{~cm}^{2} / \mathrm{s}$ for $\mathrm{O}_{2}-\mathrm{N}_{2}$ at $1550{ }^{\circ} \mathrm{C}$ and a pressure of 1 atm.

\section{Results}

\section{Flux}

Table 3 shows the average fluxes along with the calculated 95\% confidence interval for each set of experimental parameters. It should be noted that experiments with a flow rate of $51 / \mathrm{min}$ were not analyzed for flux due to the previously

Table 3 Flux results, mean values and $95 \%$ confidence intervals, for the experiments performed in this study

\begin{tabular}{llll}
\hline $\mathrm{O}_{2}$-content $(\%)$ & Gas flow rate & Mean flux $\left(\mathrm{g} / \mathrm{m}^{2} \mathrm{~s}\right)$ & $95 \% \mathrm{CI}\left(\mathrm{g} / \mathrm{m}^{2} \mathrm{~s}\right)$ \\
\hline 0 & 1 & 0.0637 & 0.0328 \\
10.5 & 1 & 0.0833 & 0.0205 \\
21 & 1 & 0.4934 & 0.0412 \\
35 & 1 & 0.5731 & 0.129 \\
50 & 1 & 0.7151 & 0.0407 \\
0 & 3 & 0.0841 & 0.0272 \\
5 & 3 & 0.6182 & 0.0798 \\
10.5 & 3 & 0.9767 & 0.0719 \\
21 & 3 & 1.8794 & 0.0703 \\
30 & 3 & 2.4501 & 0.4024 \\
50 & 3 & 2.6120 & 0.2097 \\
\hline
\end{tabular}


mentioned loss of fumes, but the dust was analyzed for size distribution in Sect. 4.3.

Figure 3 shows the measured dust fluxes from the experiments, with their respective $95 \%$ confidence intervals. The flux values for both $11 / \mathrm{min}$ and $31 / \mathrm{min}$ gas flow increase steadily at lower oxygen contents, before the curve flattens at higher oxygen contents.

\section{Elemental Distribution}

The distribution of major elements in the dust for varying bulk oxygen concentrations as well as for the HCFeMn alloy used is shown in Fig. 4 together with SiMn pilot scale results from Ma et al. [30] and shows clear relations between the concentration of most of the elements and the oxygen content in the bulk gas, i.e. for all the trace elements except phosphorous, the concentration is higher in the dust than in the metal. The elements $\mathrm{Zn}, \mathrm{Mg}, \mathrm{Pb}, \mathrm{Na}, \mathrm{S}$, and $\mathrm{Al}$ show a general trend of lowered concentration with increasing oxygen in the bulk gas, with $\mathrm{Zn}$ having an especially high concentration at low $\mathrm{O}_{2}$ levels. Si has a distinct peak at and around the regular oxygen level of $21 \%$, whereas the $\mathrm{K}$ concentration is at its lowest in the dust at the same level. P and Fe both increase significantly at the 35 and 50\% level, while staying relatively flat at lower $\mathrm{O}_{2}$ concentrations.

Figure 5 shows a SEM image of typical dust particles from an experiments with $31 /$ min flow rate of synthetic air, showing the structure of the particles. These are primarily cF8 MnO-crystals, given that more than $90 \mathrm{wt} \%$ of the dust, excluding oxygen, is manganese. The green color of the dust from the filters matches the characteristic green color of $\mathrm{MnO}$-crystals.

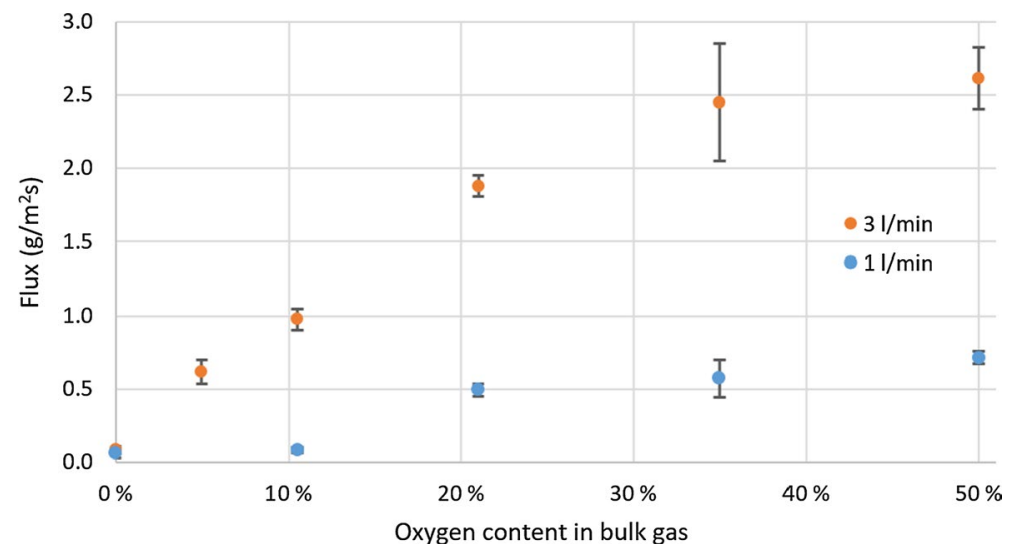

Fig. 3 Experimental data shown with $95 \%$ confidence interval bars 


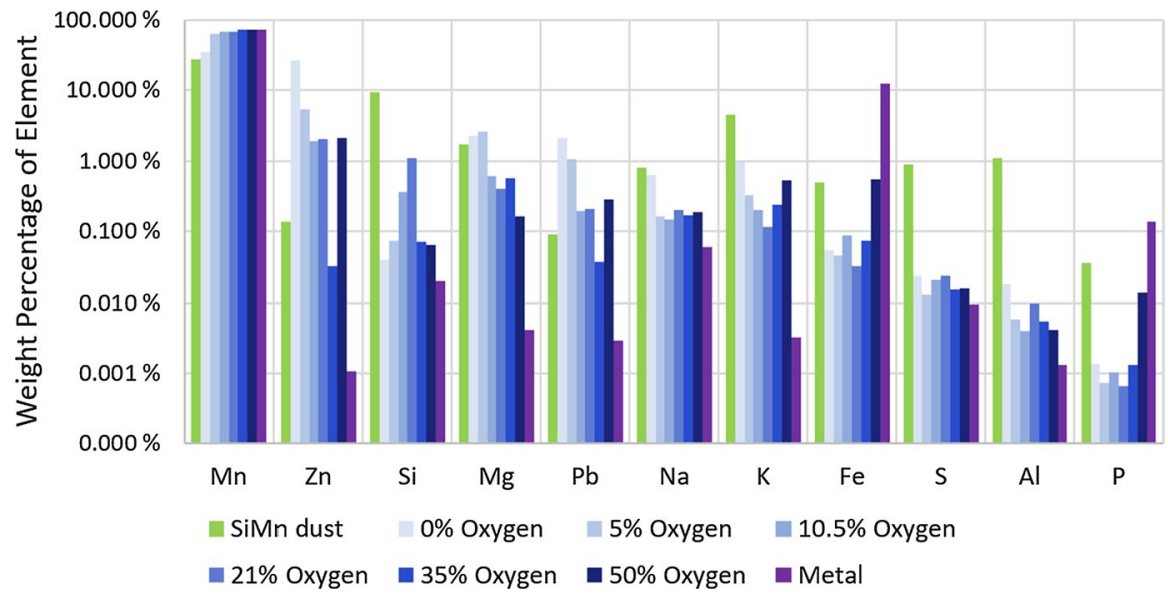

Fig. 4 Element distribution for the most relevant elements (except oxygen) as measured by ICP-MS. The purple bars refer to samples taken from the metal chips used in the experiments, while the remaining blue bars are from dust samples taken from the filter in each experiment. The green bars show SiMn pilot scale results from Ma et al. [30]. Note the logarithmic scale on the Y-axis

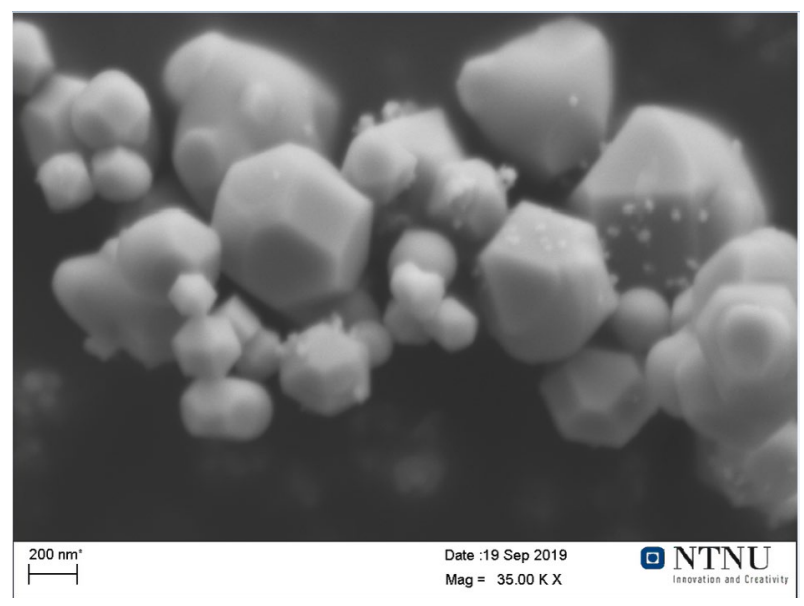

Fig. 5 SEM picture of filter dust particles from an experiment with 31/min flow rate of synthetic air

\section{Size Distribution}

Manual particle counting (PC) was performed on SEM-images of the dust from the filters. This size distribution is shown in Fig. 6a, with the mean(median) values being $113(98) \mathrm{nm}, 116(111) \mathrm{nm}$ and $1008(719) \mathrm{nm}$ for $5 \mathrm{l} / \mathrm{min} 35 \% \mathrm{O}_{2}, 5 \mathrm{l} / \mathrm{min} 10 \%$ $\mathrm{O}_{2}$, and $11 / \mathrm{min} 35 \% \mathrm{O}_{2}$, respectively. Varying oxygen content in the gas did not result in significantly different particle size distribution. 


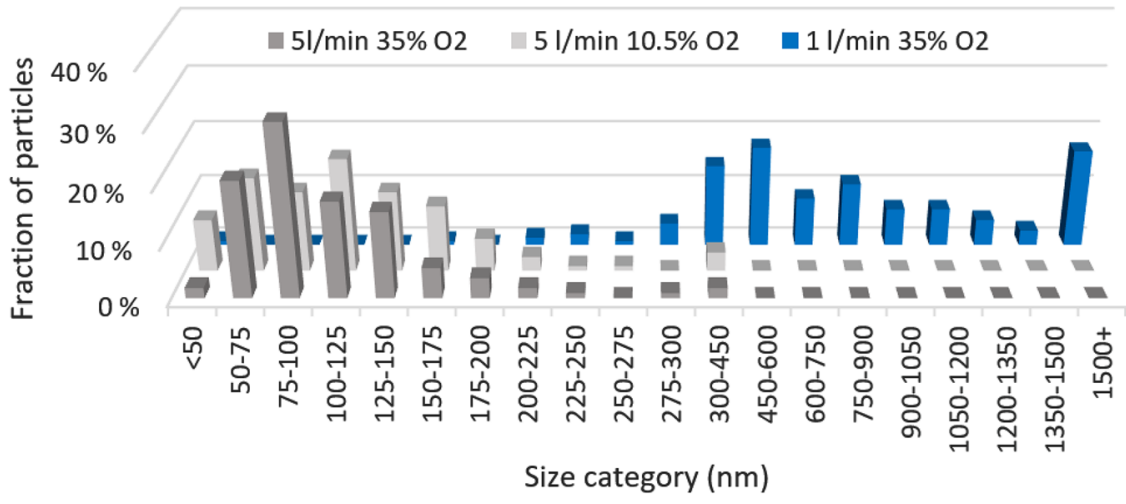

(a) Size distribution of particles from the filter dust of three experiments, measured manually from SEM-images. Note the change in box width from $300 \mathrm{~nm}$.

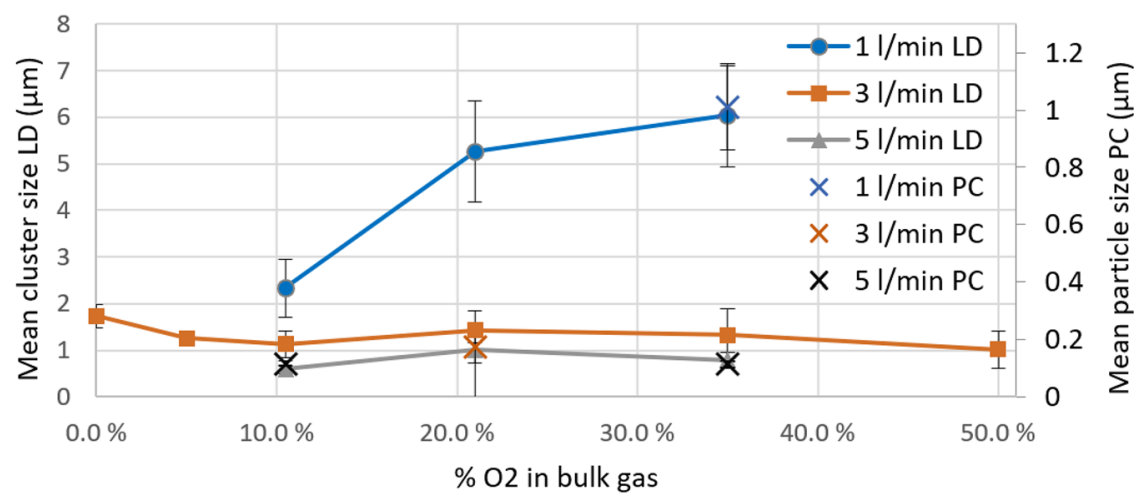

(b) LD and PC results, showing average cluster and particle sizes for each flow rate with respect to the oxygen partial pressure. Error bars show the $95 \%$ confidence interval given the data.

Fig. 6 Size distribution measured with laser diffraction and particle counting

LD was also performed on the filter samples from each category of bulk gas oxygen content and flow rate, and the resulting average particle sizes for each flow rate are shown in Fig. 6b with respect to the partial pressure, together with the average particle size from the PC. The results show a clear correlation between the mean cluster size measured with LD and the mean particle size measured through PC, with the mean cluster size being around six times larger than the mean primary particle size. The bulk oxygen concentration only had a significant impact on the dust from the $11 / \mathrm{min}$ experiments, and it overall had a lesser impact on the particle and cluster size compared to the flow rate. 


\section{Discussions}

\section{Flux}

Figure 7 shows the relation between the measured experimental flux values and the ones calculated with the formula from Rosner, together with the maximum evaporation flux calculated with Eq. 7 given the experimental conditions. It also includes data from Ma et al. [7] and Gates et al. [10] for comparison, and several maximum evaporation fluxes calculated given different assumptions. There is a good correlation between the calculated values and the experimental values up to a certain point, but there is a clear disparity between the highest experimental flux values and the theoretical maximum flux limited by Mn evaporation in vacuo.

Possible explanations for these results are:

1. The activity and subsequent vapor partial pressure of manganese on the surface is higher than calculated

2. The temperature at the surface is higher than assumed

3. The parameters or assumptions used in this paper are incorrect

To evaluate the activity of manganese it is useful to look at the oxygen utilization in the system, which gives insight into reactions at the metal surface:

Figure 8 shows the average oxygen utilization in the dust measured for the varying gas flow rates and oxygen concentrations. The oxygen utilization was typically between 15 and $50 \%$, decreasing with increasing bulk oxygen concentration in bulk gas, and was somewhat higher for $3 \mathrm{l} / \mathrm{min}$ than for $1 \mathrm{l} / \mathrm{min}$. The increase when comparing different flow rates is presumably because of the shorter diffusion distance for oxygen at higher flow rates across the melt, which in turn allows more of the oxygen to diffuse toward the surface. The decreasing utilization with increasing bulk oxygen concentration is assumed to be due to the evaporation flux limitations, which has been shown to lower the fume formation flux more with increasing bulk oxygen concentration compared to the theoretical flux given no such limit.

When the oxygen content in the gas is increased and a high flow makes the diffusion layer thin, the distance between the reaction front and the metal surface grows very short. Given such circumstances, the assumption that the reaction front is essentially a surface and has no volume might not hold true, and the chance that some oxygen molecules pass the front and reach the surface before reacting to evaporated manganese is no longer zero.

If such conditions leads to oxygen molecules reaching the surface, this has two potential interesting interactions with the fuming rate:

1. Oxygen reacts directly with liquid manganese, forming oxides on the surface.

2. Oxygen reacts with the carbon at the surface to form CO-gas. This reduces the carbon content at the surface, increasing the Mn activity as previously mentioned. 


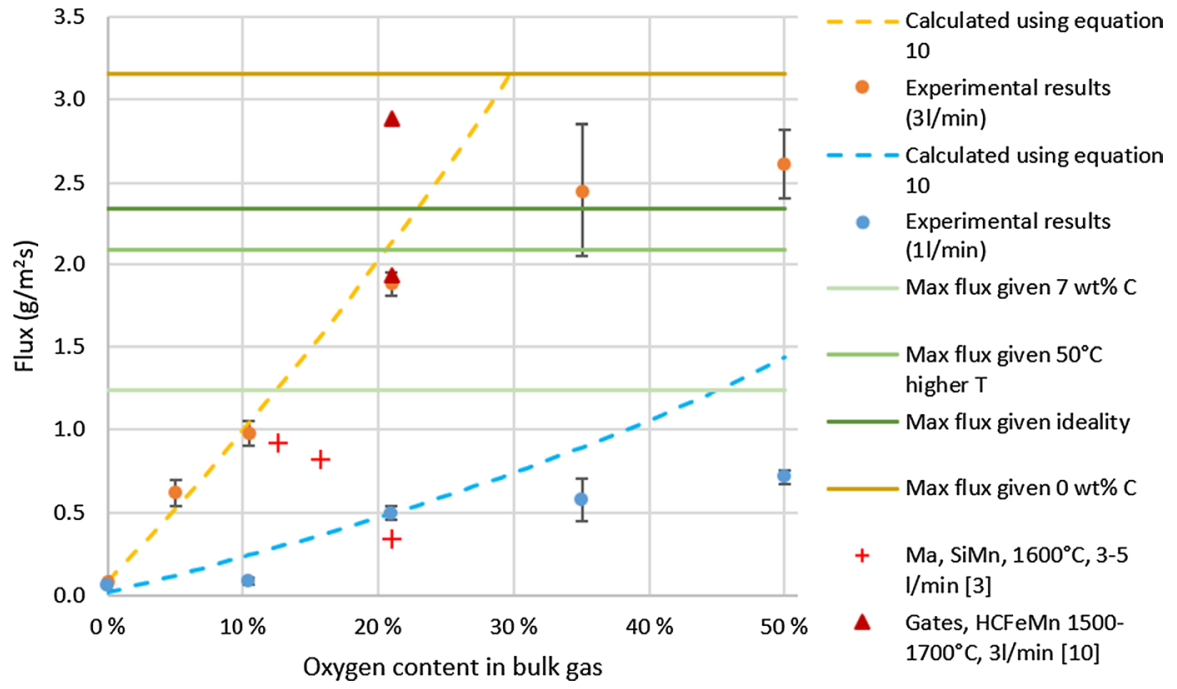

Fig. 7 Relation between the measured experimental flux values and the ones calculated with the formula from Rosner [6]. Includes the maximum evaporation flux, calculated using Eqs. 10 and 16 given four different assumptions affecting the $\mathrm{Mn}(\mathrm{g})$ partial pressure. The calculated line for $1 \mathrm{l} / \mathrm{min}$ uses $21 \%$ oxygen as the baseline due to instability in the fume generation at the lowest levels of oxygen and flow. Data from Ma et al. [7] and Gates et al. [10] are shown for comparison, but the difference in temperature, flow rate, and/or metal composition must be considered. The higher fluxes correspond to the higher flow rate and temperature for Ma and Gates, respectively

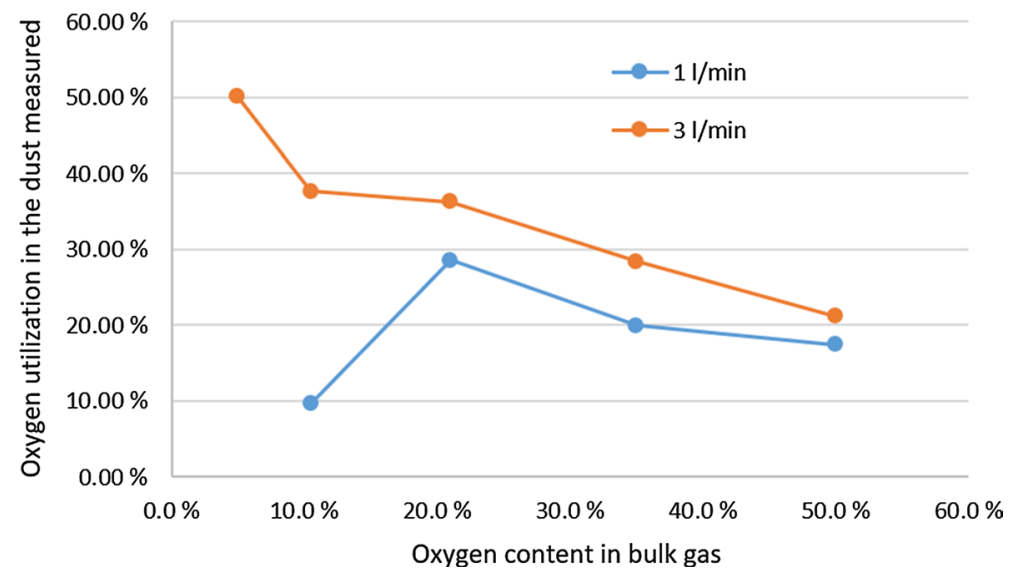

Fig. 8 Oxygen utilization over the bulk gas oxygen concentration calculated from the dust weight and oxygen flow in the experiments. The value for $10 \% \mathrm{O}_{2}$ at $1 \mathrm{l} / \mathrm{min}$ appears to be an outlier 
Little to no slag was observed during the experiments however, which should have been the case given interaction number one. This makes direct oxidation of carbon the most likely case if oxygen has reached the surface during these experiments. If that is the case, the surface could become decarburized, as the diffusion rate generally is much lower in liquids compared to gas, and as such the rate of carbon diffusing to the surface would realistically be much lower than the rate it reacts with oxygen diffusing to the surface. At temperatures between 1550 and $1650{ }^{\circ} \mathrm{C}$, oxygen is more reactive with carbon than with manganese [2], which further supports the theory of decarburization at the conditions used in this study. Furthermore, above $1650{ }^{\circ} \mathrm{C}$ the limiting factor for decarburization is carbon transfer to the gas/liquid interface, and carbon contents in the bulk as low as $0.5-1 \%$ can be achieved at temperatures approaching $1800{ }^{\circ} \mathrm{C}$ and $\mathrm{CO}$-pressures approaching $1 \mathrm{~atm}$ [25].

This is of particular interest, as the most important element affecting the activity coefficient of manganese in the melt, and subsequently the Mn vapor pressure above the liquid melt, is carbon. Lee [26] presented a formula for the activity coefficient of manganese based on the assumption that manganese and iron behave ideally, which is shown in Eq. 16:

$$
\begin{aligned}
\ln \left(\gamma_{\mathrm{Mn}}(\mathrm{Fe}-\mathrm{Mn}-\mathrm{C})\right)= & (-0.4822+576.7 / T) x_{C}+(5.1498-10842 / T) x_{C}^{2}+ \\
& (-25.821+8289.7 / T) x_{C}^{3}-4943.8 x_{C}^{4} x_{F e}^{5}
\end{aligned}
$$

where $\mathrm{n}_{i}$ is the atom fraction of species $\mathrm{i}$ for both equations and $\mathrm{T}$ is the temperature in Kelvin.

Given that the melt in our system is in contact with solid carbon, the graphite crucible, we can assume carbon saturation in the bulk melt. Using the approximation for carbon saturation levels done by Lee [26], we get a C atom fraction of 0.271, which when entered into Eq. 16 gives a Mn activity coefficient of 0.59 for a total Mn activity of 0.375 . The value calculated with the Factsage software as previously mentioned was slightly lower at 0.345 .

If we assume that the air blown on the alloy to a significant extent reaches the melt surface and decarburizes the melt surface, the result is a higher Mn concentration at the surface than in the bulk, which coupled with a higher activity coefficient results in an associated higher Mn activity and Mn vapor pressure. As the Fe-Mn system behaves close to ideally [27], the activity coefficient is close to 1 , and the activity in our system approaches 0.856 . Table 4 shows the maximum evaporation flux given different assumptions calculated with Eq. 7, 10 and 16 together with the $\mathrm{Mn}(\mathrm{l})$ activity for the same assumptions. The experimental flux values compared to the four maximum evaporation fluxes from Table 4 are shown in Fig. 7, and in reality the maximum evaporation flux should be in somewhere between these values:

Assuming no other changes, there is a 1:1 correlation between the $\mathrm{Mn}(\mathrm{l})$ activity and the evaporation flux. Changing the carbon content from 7 to $0 \mathrm{wt} \%$ more than doubles the activity, which then more than doubles the evaporation flux. This shows how sensitive the system is to changes in the carbon content, as higher carbon content both lowers the concentration of manganese and leads to a negative deviation in the manganese activity. 
Table 4 Maximum evaporation fluxes calculated with Eqs. 7, 10 and 16 based of various assumptions, with the intermediary $\mathrm{Mn}(\mathrm{l})$ activity

\begin{tabular}{lll}
\hline Assumption & $\mathrm{Mn}(\mathrm{l})$ activity & Flux $\left(\mathrm{g} / \mathrm{m}^{2} \mathrm{~s}\right)$ \\
\hline 7wt\% carbon, Factsage $\mathrm{Mn}(\mathrm{g})$ partial pressure & 0.345 & 1.239 \\
7wt\% carbon, theoretical $\mathrm{Mn}(\mathrm{l})$ activity & 0.375 & 1.381 \\
7wt $\%$ carbon, theoretical $\mathrm{Mn}(\mathrm{l})$ activity, $+50{ }^{\circ} \mathrm{C}$ & 0.375 & 2.085 \\
7wt\% carbon, ideal $\mathrm{Mn}(\mathrm{l})$ activity & 0.636 & 2.342 \\
no carbon, ideal Mn(1) activity & 0.856 & 3.152 \\
\hline
\end{tabular}

Theoretical values are calculated with Eq. 16 taking into account negative deviation from ideality between $\mathrm{Mn}, \mathrm{Fe}$, and C. Ideal values are simply the molar concentration of Mn given the different carbon contents

Ma [28] studied the fuming rates from silicomanganese where 0-2 1/min of Argon was added to a static $3 \mathrm{l} / \mathrm{min}$ flow rate of synthetic air. The result was an average flux increase of around 142 and 167\% for additional 1 and 2 1/min Argon compared to just the synthetic air. This aligns with the results of the current study, albeit the increase was lower here, which implied that the rate of oxygen toward the surface and the boundary layer thickness is of greater importance than the partial pressure of oxygen in the bulk gas. The much lower flux with SiMn when comparing the data for experiments with $3 \mathrm{l} / \mathrm{min}$ total flow rate likely stem from the difference in materials, that there is a lower fuming rate from SiMn compared to HCFeMn.

By studying the results shown in Fig. 7 it can be seen that just assuming ideality or an increased surface temperature is not enough to bring the evaporation flux above the experimental values. Assuming a carbon concentration on the surface close to 0 would be enough however, and any combination of lower carbon content, lower activity coefficient, and higher temperature could explain the high fluxes measured.

As the crucible is heated through induction, which usually implies good stirring, the melt should be reasonably isothermal, but exothermic reactions might increase local temperatures [9]. From reaction equations and Gibbs energy calculations [7, 8], one mole of liquid manganese evaporating and then reacting with half a mole of oxygen gas to form $\mathrm{MnO}(\mathrm{s})$-particles yields a net positive of $223.43 \mathrm{~kJ}$. A mean of $0.00757 \mathrm{~g} / \mathrm{s}$ oxygen reacts to form $\mathrm{MnO}_{x}$ during the $3 \mathrm{l} / \mathrm{min} 50 \% \mathrm{O}_{2}$ experiments. the O:Mn stoichiometry $\mathrm{X}$ in MnOx dust is presumably close to 2 in the final dust, and it would as such be a reasonable assumption that half of that amount reacts inside the diffusion layer, which leads to a reaction heating effect of around $52.85 \mathrm{~W}$. Reactions between carbon and oxygen at the surface would yield additional heating effect, but the amount is not quantifiable given the accessible data.

Another note on activities can be made when comparing the fluxes measured here with the experiments done on silicomanganese by Ma et al. [7]. The average flux at $1550{ }^{\circ} \mathrm{C}$ with $31 / \mathrm{min}$ synthetic air was measured to be around $0.12 \mathrm{~g} / \mathrm{m}^{2} \mathrm{~s}$, with a majority of the dust being from manganese and less from silicon, far below the 1.88 $\mathrm{g} / \mathrm{m}^{2} \mathrm{~s}$ measured with ferromanganese. The negative deviation from ideality from mixing $\mathrm{Mn}$ and $\mathrm{Si}$ is particularly strong, with the activity of Mn being in the area 
of $0.1-0.2$ given the $68 \mathrm{wt} \% \mathrm{Mn}, 17.6 \mathrm{wt} \% \mathrm{Si}$ in the aforementioned silicomanganese [29].

The fluxes measured by Gates et al. $[10,11]$ were comparable to the ones measured in this study for dry air at the same flow rate and similar temperature, with a downward trend as the water vapor partial pressure was increased and a larger flux when the temperature was increased. The $\mathrm{ZnO}$ found in the dust from high vapor experiments is also similar to the increased $\mathrm{ZnO}$ fraction in the dust from experiments with lower $\mathrm{O}_{2}$ content in this study.

A note must be made on $\mathrm{Y}_{\mathrm{M}, w}$, as the value is calculated based on the assumption that $\mathrm{N}_{2}$ constitutes the remainder of the gas at the gas-metal interface, but given the content of the metal used Na-vapor could be a large component as well, which could change the value of $\mathrm{Y}_{\mathrm{M}, w}$ slightly as $\mathrm{Na}(\mathrm{g})$ is somewhat lighter than $\mathrm{N}_{2}(\mathrm{~g})$. This change however, has a small effect compared to the other relevant factors.

The flux results are relevant for reducing dust in the metal production industry by virtue of increasing our understanding of the influence the different factors have on the amount of fumes produced, in addition to improving our knowledge on how these factors influence elemental and size distribution as discussed in the following sections. Comparing the theoretical maximum evaporation fluxes with the experimental data give insight to which conditions are likely to have been the case at the metal surface, where decarburization of the surface and increased temperatures have been identifies as likely causes for the high fuming rates, in addition to high flow rates and high oxygen content in the gas. The results in this work imply that any implementation that reduces the temperature of the metal surface, lowers the flow of air across it, lowers the amount of oxygen that reaches the surface, or increases the amount of carbon at the surface will contribute to reducing the fuming rate. An example would be addition of water vapor which reduced the temperature and also lowers the oxygen concentration, and which already has been tested at melting plants [11].

\section{Elemental Distribution}

The trend of decreasing element concentration for the majority of the trace elements is theorized to be due to the excess of manganese compared to these elements. As the amount of oxygen is increased, the flux also increases, which would deplete the metal surface of the trace elements more quickly than at lower oxygen concentrations and fluxes. This is not the case for iron, and the similarities between the curves for iron and phosphorous may be due to strong negative interactions between the two elements.

Ma et al. [30] studied the elemental distribution in the silicomanganese production, where they found that base and transition metal elemental distribution mostly behave in good accordance with Gibbs energy of oxidation, while alkali metals fuming is controlled by their low boiling point. The most prevalent elements in the dust from pilot scale experiments were in order: $\mathrm{Mn}, \mathrm{Si}, \mathrm{K}, \mathrm{Ca}, \mathrm{Mg}, \mathrm{Al}, \mathrm{S}, \mathrm{Na}, \mathrm{Fe}, \mathrm{Ba}$, $\mathrm{B}, \mathrm{Zn}, \mathrm{Pb}, \mathrm{Sr}$, P. This matches fairly well with the distribution found in this study, 
given that $\mathrm{Mn}, \mathrm{Fe}$ and $\mathrm{Si}$ concentrations in the metal are different, and that $\mathrm{Ca}, \mathrm{Ba}$, $\mathrm{B}$, and $\mathrm{Sr}$ were not screened for in this study. The most notable differences are the high amount of $\mathrm{Zn}$ and the low amount of $\mathrm{Al}, \mathrm{S}$ and $\mathrm{P}$ in the FeMn dust, compared to the SiMn dust.

\section{Size Distribution}

The most notable information from the size distribution results is the clear increase in particle and cluster size when the flow rate is lowered, especially when going from 3 to $11 / \mathrm{min}$. This is assumed to be because the time that particles and clusters have to grow is inversely proportional to the gas flow rate, and the relative change in growth time is as such much larger when going from 3 to $11 /$ min than from 5 to $3 \mathrm{l} /$ min. The flow rate has a much larger effect on particle size compared to the oxygen content, which only yields a large difference in average size for the lowest flow rate.

The average size for both methods match well when comparing different flow rates and oxygen content, with the LD results being around six times larger than the PC measurements for each set of parameters. This indicates that the difference between the cluster size measured with LD and the individual particle size measured directly in SEM-images is similar regardless of the experimental parameters. A parallel can be made to the work of Gates et al. [11] where the size distribution measured showed a clear increase in mean particle size when adding water vapor. Their work also showed a significant decrease in size when comparing fumes that had traveled a shorter distance to those that had travelled further, which aligns well with the results from the current study.

\section{Conclusions}

A model based on the work of Rosner [6] was compared to experimental results for the fuming rates of high-carbon ferromanganese at $1550{ }^{\circ} \mathrm{C}$ blown with air at varying oxygen concentrations and flow rates. Dust from the experiments were also analyzed with ICP-MS, LD, and SEM, to study the elemental and size distributions. From this work, the following conclusions may be drawn:

On the fuming rates comparing with Rosner's theories [6]:

- The fuming flux seems to follow the theoretical rate up to a certain $\mathrm{O}_{2}$ concentration as described by Rosner, and then tapers off concurring with Rosner's theory, but toward a higher flux than the theoretical evaporation rate limit given bulk alloy composition at the metal surface. Some factor is believed to increase the flux beyond the value limited by evaporation in vacuo.

- A theory for the high flux rates is that the activity of manganese is higher at the surface than in the bulk phase, possibly due to the carbon-manganese interaction being weakened through either a lower carbon content at the surface, or that manganese and carbon behaves closer to ideality at the surface due to the different conditions compared to the bulk phase. Lowered surface carbon content 
could be because oxygen reaches the surface and decarburizes it. The temperature could also be higher at the surface, which would increase evaporation, possibly due to exothermic reactions happening at or above the surface of the melt.

On the elemental distribution:

- The concentration of most trace elements was found to decrease as the oxygen content increased, which is believed to be due to depletion at the metal surface being a factor at higher total fluxes.

- Iron and phosphorous both increased sharply at the highest oxygen concentrations at a very similar rate, and there is reason to believe there is a connection between the two elements that is the cause. In the metal, there is a strong affinity between iron and phosphorous which leads to iron affecting the phosphorous vapor pressure [30], and this property may carry over to the dust.

On the size distribution:

- The size of both individual fume particles and clusters increases when the flow rate is reduced.

- The average size for both clusters and particles increases at a similar rate, with the clusters having an average radii of around six times the individual particle average.

- The flow rate was found to have a much larger effect on the size distribution compared to the oxygen content, especially at low flow rates.

Acknowledgements The authors would like to thank the Centre for Research-Based Innovation (SFI Metal Production, NFR Project Number 237738) for funding the project. UNINETT Sigma2 - the National Infrastructure for High Performance Computing and Data Storage in Norway is acknowledged for a generous grant of computer time (project NN9353K). The authors would also like to thank Erlend Lunnan Bjørnstad for contributing with comments and discussions throughout the work.

Funding Open access funding provided by NTNU Norwegian University of Science and Technology (incl St. Olavs Hospital - Trondheim University Hospital). Funding is provided by the Centre for Research-Based Innovation (SFI Metal Production, NFR Project Number 237738).

Availability of data and material Not applicable

\section{Declarations}

Conflicts of interest The authors are aware of no conflicts of interest.

Code availability Not applicable

Open Access This article is licensed under a Creative Commons Attribution 4.0 International License, which permits use, sharing, adaptation, distribution and reproduction in any medium or format, as long as you give appropriate credit to the original author(s) and the source, provide a link to the Creative Commons licence, and indicate if changes were made. The images or other third party material in this article are included in the article's Creative Commons licence, unless indicated otherwise in a credit line to the 
material. If material is not included in the article's Creative Commons licence and your intended use is not permitted by statutory regulation or exceeds the permitted use, you will need to obtain permission directly from the copyright holder. To view a copy of this licence, visit http://creativecommons.org/licen ses/by/4.0/.

\section{References}

1. S.E Olsen, M. Tangstad and T. Lindstad, Production of Manganese Ferroalloys. 1st ed.; (SINTEF and Tapir Academic Press: Trondheim, Norway, 2007); pp. 11-69.

2. B.-D. You, B.-W. Lee and J.-J. Pak, Metals and Materials, 5, 497 (1999).

3. S. Gunst, S. Weinbruch, M. Wentzel, H. M. Ortner, A. Skogstad, S. Hetland and Y. Thomassen, Journal of Environmental Monitoring, 2, 65 (2000).

4. C. Wagner, Journal of Applied Physics 29, 1295 (1958).

5. E. T. Turkdogan, P. Grieveson and L. S. Darken, Journal of Physical Chemistry 67(8), 1647 (1963).

6. D. E. Rosner, Oxidation of Metals 4(1), 1 (1972).

7. Y. Ma, I. Kero and G. Tranell, Oxid Met, https://doi.org/10.1007/s11085-017-9780-y.

8. Factsage, Factsage 7.3 2019, http://www.Factsage.com/.

9. Y. E. Lee and L. Kolbeinsen, ISIJ International 45(9), 1282 (2005).

10. S. J. Gates, G. Kornelius, I. Kero and G. M. Tranell, The Influence of Water Vapour on the Fuming Rate in a Ferromanganese System, Energy Materials 73 (2017).

11. S. J. Gates , I. Kero, L. Hunsbedt and G. M. Tranell, How water mist alters the fuming rate and particle agglomeration during ferromanganese casting Conference article: Infacon XV, Southern African Institute of Mining and Metallurgy (SAIMM) (2018).

12. I. Kero, D. Slizovskiy, B. Wittgens and G. Tranell, Fume Formation From Liquid Ferromanganese. Conference article: Sustainable Industrial Processing Summit 2015, volume 3, FLOGEN.

13. M. K. Næss, J. E. Olsen, S. Andersson and G. Tranell, Oxid Met 82, 395 (2014).

14. Malvern Panalytical Laser Diffraction (LD), Particle size distributions from nanometers to millimeters. https://www.malvernpanalytical.com/en/products/technology/light-scattering/laser-diffraction, Visited 22.01.2021.

15. Coulter International Corporation COULTER LS Series. http://www.cyto.purdue.edu/cdroms/ cyto2/6/coulter/ss000096.htm, Visited 27.01.2021.

16. S.-W. Joo, S.-H. Hong, G.-H. Lee and B.-D. You, Metals and Materials 19(3) 585 (2013).

17. S. Chapman and T. G. Cowling, The Mathematical Theory of Non-Uniform Gases. 3rd ed; (Cambridge University Press, 1970).

18. R.B. Bird, W. E. Stewart and E. N. Lightfoot, Transport Phenomena. 2nd ed. (Wiley, 2007).

19. H. A. H. Olsen, S. Andersson and G. Tranell, Evaporation and Diffusion of Mn in Inert Systems. CFD Modeling and Simulation in Materials Processing 2018, The Minerals, Metals \& Materials Series (Springer, 2018).

20. R. A. Kendall, T. H. Dunning Jr. and R. J. Harrison, The Journal of Chemical Physics 966796 (1992).

21. N. B. Balabanov and K. A. Peterson, The Journal of Chemical Physics 123064107 (2005).

22. CFOUR, a quantum chemical program package written by J.F. Stanton, J. Gauss, L. Cheng, M.E. Harding, D.A. Matthews, P.G. Szalay with contributions from A.A. Auer, R.J. Bartlett, U. Benedikt, C. Berger, D.E. Bernholdt, Y.J. Bomble, O. Christiansen, F. Engel, R. Faber, M. Heckert, O. Heun, M. Hilgenberg, C. Huber, T.-C. Jagau, D. Jonsson, J. Jusélius, T. Kirsch, K. Klein, W.J. Lauderdale, F. Lipparini, T. Metzroth, L.A. Mück, D.P. O’Neill, D.R. Price, E. Prochnow, C. Puzzarini, K. Ruud, F. Schiffmann, W. Schwalbach, C. Simmons, S. Stopkowicz, A. Tajti, J. Vázquez, F. Wang, J.D. Watts and the integral packages MOLECULE (J. Almlöf and P.R. Taylor), PROPS (P.R. Taylor), ABACUS (T. Helgaker, H.J. Aa. Jensen, P. Jørgensen, and J. Olsen), and ECP routines by A. V. Mitin and C. van Wüllen. For the current version, see http: / / www . cfour. de.

23. D.A. Matthews, L. Cheng, M. E. Harding, F. Lipparini, S. Stopkowicz, T. C. Jagau, P. G. Szalay, J. Gauss and J. F. Stanton, The Journal of Chemical Physics 152214108 (2020).

24. F. J. Smith and R.J. Munn, The Journal of Chemical Physics 413560 (1964).

25. M. Gasik Handbook of Ferroalloys, Theory and Technology (Elsevier Ltd., ISBN 978-0-08-0977539, 2013). 
26. Y. E. Lee, Metallurgical and Materials Transactions 29B 397 (1998).

27. A. Tanaka, Trans. JIM 2127 (1980).

28. Y. Ma, Oxidation and Fume Formation During Production of Si and Mn-based alloys Doctoralthesis, Norwegian University of Science and Technology. Trondheim, October 2018.

29. J. Safarian, L. Kolbeinsen and M. Tangstad. Journal of Materials Science 47, 5561 (2012).

30. Y. Ma, Metallurgical and Materials Transactions B 49, 2444 (2018).

Publisher's Note Springer Nature remains neutral with regard to jurisdictional claims in published maps and institutional affiliations. 